\title{
A MUSASHI-RELATED PROTEIN IS ESSENTIAL FOR GAMETOGENESIS IN ARABIDOPSIS
}

Laura A. Moody ${ }^{1}$, Ester Rabbinowitsch², Hugh G. Dickinson, Roxaana Clayton, David M. Emms \& Jane A. Langdale

Department of Plant Sciences, University of Oxford, South Parks Rd., Oxford, OX1 3RB, UK

${ }^{1}$ For correspondence: laura.moody@plants.ox.ac.uk

${ }^{2}$ Current address: Scientia Terrae, Fortsesteenweg 30A, B-2860 Sint-Katelijne-Waver, Belgium 


\section{SUMMARY}

Musashi (Msi) proteins are an evolutionarily conserved group of RNA-binding proteins, required for targeted control of mRNA translation during many important developmental processes in animals. Most notably, Msi proteins play important roles during both spermatogenesis and oogenesis. Msi proteins also exist in plants but these are largely uncharacterized. Here we report the functional characterization of an Arabidopsis Msi ortholog ABORTED GAMETOPHYTE 2 (AOG2), which encodes a protein containing two RNA recognition motifs and an ER-targeting signal. AOG2-GFP translational fusions were localized to the ER in transient assays, suggesting that AOG2 most likely binds to ER-targeted mRNAs. We show that disrupted $A O G 2$ function leads to a high rate of both ovule and seed abortion, and that homozygous loss of function mutants are embryo lethal. Furthermore, we demonstrate that $A O G 2$ is required to establish asymmetry during pollen mitosis I, and that loss of AOG2 function leads to loss of pollen viability. Collectively the results reveal that AOG2 is required for the establishment of polarity and/or the progression of mitosis during gametophyte development in Arabidopsis, and thus Msi-related proteins have an evolutionarily conserved role in gametogenesis in both animals and plants.

\section{SIGNIFICANCE STATEMENT (75 WORDS) = 2 SENTENCES MAX}

ABORTED GAMETOPHYTE 2 (AOG2) encodes a Musashi-related RNA-binding protein that is required for gametogenesis and embryogenesis in Arabidopsis. AOG2 is required for the establishment of polarity and/or the progression of mitosis during gametophyte development in Arabidopsis, and thus Musashi-related proteins have an evolutionarily conserved role in gametogenesis in both animals and plants. 


\section{INTRODUCTION}

Musashi (Msi) proteins belong to an evolutionarily conserved group of RNA-binding proteins, which are characterized by the presence of two RNA recognition motifs (RRMs) (Sutherland et al., 2013). Msi proteins are essential for the targeted control of mRNA translation, and many of the known Msi targets (e.g. Numb, a negative regulator of Notch signaling) play key roles in oncogenic pathways. Consequently, mis-regulation of Msi proteins is a major contributing factor in cancers and other diseases (Guo et al., 1995; Guo et al., 1996; Zhong et al., 1996; Lan et al., 2017; Zhang et al., 2014; Kharas et al., 2010; Ito et al., 2010; Griner et al., 2010; Kaeda et al., 2015; Li et al., 2015; Zong et al., 2016; Kudinov et al., 2016; Guo et al., 2017; Cox et al., 2013).

The Msi protein was originally identified as a neural RNA-binding protein that is essential for an asymmetric cell division in the Drosophila sensory organ. In WT, the sensory organ precursor (SOP) cell divides asymmetrically to give rise to a non-neuronal (Ila) and a neuronal (Ilb) precursor cell. Socket and shaft cells of the external sensory organ of Drosophila are products of Ila cells whereas neurons and glia are products of Ilb cells. In loss of msi mutants, the SOP undergoes an abnormal symmetric cell division to give rise to an overrepresentation of Ila cells, with no Ilb cells. Consequently, sensory organs comprise only socket and shaft cells, and mutants exhibit a double bristle phenotype. This phenotype bears a resemblance to the two-sword fighting Japanese Samurai Miyamoto Musashi (Nakamura et al., 1994).

Msi proteins also play an important role during gametogenesis, and the role of Musashi-2 (Msi2) in both spermatogenesis and oogenesis has been well described. For example, in mice, Msi-2 is highly expressed in meiotic spermatocytes and differentiating spermatids and is required to maintain a pool of spermatogonial stem cells (Siddall et al., 2006; Sutherland et al., 2014). Loss of Msi-2 function leads to premature differentiation of spermatids, and Msi-2 overexpression causes male sterility (Sutherland et al., 2015; Sutherland et al., 2018). During 
spermatogenesis, Msi-2 is required for the post-transcriptional regulation of both Tbx1 and Piwil1 mRNA (Sutherland et al., 2018). Msi-2 is also highly expressed during folliculogenesis and loss of Msi-2 function causes defective follicle development in the mouse ovary (Gunter and McLaughlin, 2011; Sutherland et al., 2015). Within Xenopus oocytes, Msi-2 binds to the 3'UTR of Mos mRNA during meiotic cell cycle progression and oocyte meiotic cell cycle progression is blocked when Msi-2 is prematurely truncated (Charlesworth et al., 2006).

Here we report the functional characterization of ABORTED GAMETOPHYTE 2 (AOG2), a Msi-related protein in Arabidopsis. Loss of function mutant phenotypes reveal that AOG2 is required for both male and female gametophyte development, and for embryogenesis. Notably, asymmetric cell divisions are perturbed during pollen mitosis I, leading to loss of pollen viability in mutant plants. A role for Msi-related genes in both the establishment of asymmetry and the formation of gametes is thus conserved in animals and plants.

\section{RESULTS \& DISCUSSION}

\section{Eight Msi orthologs are present in the Arabidopsis genome}

To identify Msi2 orthologs in Arabidopsis, Orthofinder software (Emms \& Kelly, 2015) was used to interrogate 11 genome sequences representing fungi, invertebrate and vertebrate animals, algae, plus non-flowering and flowering (both monocot and eudicot) plants. An orthogroup of 46 sequences was identified and aligned using Mergalign (Collingridge \& Kelly, 2012) (Data S1-S3). Phylogenetic inference revealed an early duplication in the ophistokont lineage that generated separate Msi and Daz-associated protein (Dazap) clades, both of which are retained in the four animal genomes investigated (Figure 1). An early duplication is also inferred in the archeoplastida lineage. One of the resultant clades ('plants l') comprises single Arabidopsis (At1g17640) and moss (Physcomitrella patens) genes plus duplicated algal (Chlamydomonas reinhardtii) and monocot (Oryza sativa, Sorghum bicolor) genes. One of the Msi genes from C. reinhardtii (Cre12.g560300.t1.2) has previously been shown to play a role 
in thermal signalling but phylogenetic analyses in the same study did not identify the second (Cre07.g330300.t1.2) (Li et al., 2018). Although algal genes are not represented in the second clade ('plants II'), multiple duplications are evident in each of the 5 plant genomes. Arabidopsis has seven genes in this clade - At1g58470, At5g47620, At3g07810 plus recent duplicate pairs At5g55550/At4g26650 and At4g14300/At2g33410.

Expression profiles of all seven Arabidopsis Msi orthologs in the 'plants II' clade were interrogated using GENEVESTIGATOR (Zimmermann et al., 2004). Transcripts of two of the genes (At1g58470 and At2g33410) were enriched in the embryo, endosperm and seed coat. Four of the genes (At5g47620, At3g07810, At5g55550, At4g26650), which likely arose from within-eudicot or within-species duplications, were expressed most highly in pollen. One of the genes (At4g14300) was moderately expressed in both pollen and the embryo (Figure 2). The protein encoded by gene $A t 3 g 07810$ is a Reciprocal Best Hit of metazoan MSI2 and vice versa, and as such is regarded as the closest MSI2 ortholog in Arabidopsis. To confirm that the protein encoded by the At3g07810 gene accumulates in pollen, transgenic lines were generated in which $2.2 \mathrm{~kb}$ of the promoter was used to drive expression of a translational fusion between the entire open reading frame (ORF) and the green fluorescent protein (GFP) reporter. The ORF-GFP fusion protein was diffusely localised to the cytoplasm of pollen grains (Figure S1). Based on these observations, we hypothesized that the Arabidopsis Msi2 ortholog plays a role in pollen development.

\section{The Arabidopsis Msi2 ortholog AOG2 encodes a non-nuclear RNA-binding protein}

The Msi2 ortholog At3g07810, which we named ABORTED GAMETOPHYTE 2 (AOG2), encodes a protein of 495 amino acid residues with two RNA recognition motifs (RRM) at the $\mathrm{N}$ terminus, both of which are very similar to those in human Msi2 (73.7\% RRM1, 66.7\% RRM2 (Figure 3a, Figure S2). An endoplasmic reticulum (ER) targeting signal was identified within RRM2 (using LocSigDB; Negi et al., 2015), and translational fusions with the reporter protein 
GFP were targeted to the ER in transient protoplast assays (Figure 3b). AOG2 therefore most likely binds to ER-localized RNAs in Arabidopsis and given the known function of animal orthologs most likely inhibits translation of the bound transcripts.

\section{Gametophyte development is perturbed in aog2 mutants}

To determine the function of AOG2 in planta, a T-DNA insertion line was obtained from the SALK collection (http://signal.salk.edu/cgi-bin/tdnaexpress) (Alonso et al., 2003). The SALK_007316 (aog2-1) line has a T-DNA insertion positioned between the open reading frames of two genes (AOG2 and At3g07800 which encodes the thymidine kinase AtTK1) (Figure 4a). The genomic arrangement is such that the T-DNA insertion could potentially influence the promoter activity of either or both of the flanking genes. However, it has previously been reported that null mutants of AtTK1 are phenotypically indistinguishable from WT, and that gene function is associated with cell proliferation (Clausen et al., 2012, Xu et al., 2015). We thus concluded that any defects in pollen development in aog2-1 mutants would be caused by reduced activity of $A O G 2$ rather than AtTK1, although the potential for synergistic effects could not be disregarded at this stage. Notably, AOG2 expression levels were substantially reduced in aog2-1 mutant pollen relative to WT (Figure 4b).

Prior to phenotypic characterization, mutant lines were backcrossed to WT Col-0 plants. aog21/AOG2 heterozygous plants were phenotypically indistinguishable from WT, except that mean silique lengths were significantly shorter (aog2-1/AOG2 -11.40 $\pm 0.25 \mathrm{~mm}$; WT $-15.88 \pm$ $0.46 \mathrm{~mm}$ ) (Figure 4c) and the mean number of seeds per silique was significantly lower (aog21/AOG2 $-17.20 \pm 1.28 ;$ WT $-55.3 \pm 1.56$ ) (Figure 4d). Given that reduced seed-set is observed in heterozygous plants, the aog2-1 mutant allele either has a dominant effect in the diploid embryo or a recessive effect in the haploid gametophytes. Pollen-preferential AOG2 expression in WT plants, reduced AOG2 transcript levels in pollen from aog2-1/AOG2 plants, 
and the observed seed-set phenotype are all consistent with a role for AOG2 in Arabidopsis gametophyte development.

\section{Transmission through both male and female gametes is perturbed in aog 2 mutants}

To test whether the reduced seed-set in aog2-1/AOG2 heterozygotes resulted from compromised male (pollen) and/or female (megagametophyte) function, transmission efficiencies were quantified. The progeny of reciprocal test crosses between aog2-1/AOG2 and WT plants were genotyped for the presence of the mutant aog2-1 allele, and the transmission efficiency was deduced by calculating the percentage of aog2-1/AOG2 individuals in the offspring. Only $32.6 \%$ of male gametes and $26.3 \%$ of female gametes carrying the aog2-1 mutation were successfully transmitted to the next generation (Figure 5a). As such, $A O G 2$ is required for both male and female gametophyte development.

To characterize the homozygous mutant phenotype, F2 progeny of self-pollinated aog21/AOG2 heterozygotes were analysed. Strikingly, no homozygous individuals were recovered in the offspring of aog2-1/AOG2 plants. To determine whether defective transmission of the aog 2-1 allele was sufficient to account for this finding, the frequencies of WT, heterozygous and homozygous individuals amongst self-progeny of aog2-1/AOG2 plants were predicted on the basis of the quantified transmission efficiencies (Figure $5 b, 5 c$ ). In a genotyped population of over 500 F2 progeny, heterozygote frequency was as predicted $(41.7 \%$ predicted versus $40.2 \%$ observed) and WT frequency was higher than expected (49.7\% predicted versus $59.8 \%$ observed). Homozygous individuals were not identified despite a predicted frequency of $8.6 \%$ (i.e. 45 individuals in the population tested). This observation indicates that in addition to roles in gametophyte development, $A O G 2$ function may be required for development of the diploid embryo. 
To confirm that loss of $A O G 2$ function was responsible for the gametophyte and embryo defects observed in mutant plants, aog2-1/AOG2 plants were transformed with a construct in which $2.2 \mathrm{~kb}$ of the $A O G 2$ promoter was used to drive expression of the AOG2 coding sequence. In segregating T2 populations, homozygous aog2-1/aog2-1 individuals that also contained the transgene were viable, confirming that the transgene complemented gametophyte defects. However, the silique length in these aog2-1/aog2-1/AOG2 individuals was less than that seen in aog2-1/AOG2 heterozygotes (Figure 6a-e). This observation suggests either that the silique phenotype is influenced by the proportion of mutant and WT alleles present, or that the regulatory sequences (promoter and/or UTRs) used in the transgene construct were not sufficient to replicate the spatial and temporal patterns of $A O G 2$ expression that are required to fully complement the aog2-1 mutation.

\section{AOG2 is required for both female gametophyte and embryo development}

To investigate how loss of AOG2 function specifically affects female gametophyte development, siliques from aog2-1/AOG2 plants were dissected. Notably, a significant proportion (approximately $50 \%$ ) of ovules aborted prior to fertilization as evidenced by empty spaces in the ovary (Figure 7a-d). In addition, a high rate of seed abortion was observed in siliques derived from aog2-1/AOG2 $(10.81 \pm 2.71)$ plants compared to WT $(1.03 \pm 0.38)$ (Figure 7e). Mature siliques of aog2-1/AOG2 heterozygous plants thus contained a mixture of fully developed and embryo-arrested seeds. Developmental arrest was observed as early as the 2-cell stage (Figure 7f) but was also observed at the late globular (Figure $7 \mathrm{~g}$ ) and late heart stages (Figure $7 \mathrm{~h}$ ). Collectively these observations confirm a role for AOG2 both in female gametophyte and embryo development.

\section{AOG2 is required for pollen mitosis I}

To determine the role of $A O G 2$ in male gametophyte development, pollen viability was first observed using Alexander staining, which stains the cytoplasm of viable pollen grains red and 
that of non-viable or aborted grains green (Figure 8a-c). Quantification revealed that the mean number of viable mature pollen grains per anther was significantly reduced in aog2-1/AOG2 plants $(87.83 \pm 10.80)$ compared to WT $(213.44 \pm 11.72)$ (Figure $8 d)$, consistent with the observed transmission efficiency of $48 \%$ (Figure $5 a$ ).

To understand how the aog2 mutation affects pollen development, DAPI-stained mature pollen grains were examined by confocal microscopy. In WT plants, the development of pollen grains begins with the formation of diploid mother cells (i.e. meiocytes), which divide meiotically to form four haploid unicellular microspores. Each microspore subsequently divides asymmetrically during pollen mitosis I (PMI) to produce two unequal daughter cells; a vegetative cell and a generative cell. The vegetative cell adopts a terminal cell fate whereas the generative cell divides once more during pollen mitosis II to produce two sperm cells, enclosed within the cytoplasm of the vegetative cell. Mature pollen that is released from the anthers contains three cells (tricellular pollen) (Figure 8a). In WT DAPI-stained pollen, tricellular pollen was invariably detected in which one vegetative nucleus and two sperm nuclei were easily distinguishable (Figure 8e). However, in aog2-1/AOG2 DAPI-stained pollen, a roughly equal mixture of both tricellular pollen (Figure 8f) and aborted unicellular microspores (Figure $8 \mathrm{~g}$ ) were detected. Loss of AOG2 function thus prevented pollen mitosis I.

To confirm that aog2-1 pollen is unable to undergo normal pollen mitosis, cryostat-sectioned anthers were DAPI stained. In samples from aog2-1/AOG2 plants, normal PMI was observed in approximately half of the microspores observed but in the other half a symmetric cell division gave rise to two nuclei of unknown fate (Figure 8h-k). Microspores that exhibited defects in PMI did not proceed beyond the vacuolar microspore stage. Collectively these results demonstrate that $A O G 2$ is required for the asymmetric cell division at PMI that produces the vegetative and generative cells, and that loss of function leads to loss of pollen viability. 


\section{Conclusion}

The aog2-1 mutant phenotypes, namely disrupted asymmetric cell division during PMI, reduced transmission efficiencies of both male and female gametes, and perturbed embryo development are similar to those reported for mutations in GEMINI POLLEN 1 (GEM1 - also known as MOR1) (Park et al., 1998; Park and Twell, 2001; Whittington et al., 2001; Twell et al., 2002), GEM2 (Park et al., 2004) and GEM3 (also known as AUGMIN SUBUNIT 6) (Oh et al., 2016). GEM1 encodes a microtubule-associated protein and GEM3 is required for microtubule organisation and mitotic progression. Additional proteins that are essential for gametophyte development include ABORTED GAMETOPHYTE 1 (Cui et al., 2015), the DC1domain protein VACUOLELESS GAMETOPHYTES (D'Ippólito et al., 2017), and the leucinerich repeat protein PIRL6 (Forsthoefel et al., 2018). Whether AOG2 acts upstream or downstream of these other factors remains to be determined, but if any of them are translated in the ER, they are putative AOG2 targets.

\section{EXPERIMENTAL PROCEDURES}

\section{Phylogeny construction}

Genome sequences of yeast (Saccharomyces cerevisiae), fruitfly (Drosophila melanogaster), zebrafish (Danio rerio), mouse (Mus musculus) and human (Homo sapiens) were extracted from ENSEMBL (www.ensembl.org/index.html), and those of the alga Chlamydomonas reinhardtii, the moss Physcomitrella patens, the eudicots thalecress (Arabidopsis thaliana) and bean (Phaseolus vulgaris), plus the monocots rice (Oryza sativa) and sorghum (Sorghum bicolor) were extracted from Phytozome (www.phytozome.jgi.doe.gov/pz/portal.html). 99 sequences comprising the orthogroup that includes the mouse msi2 gene were retrieved using Orthofinder (Emms and Kelly, 2015) (Data S1) and aligned using Mergalign (Collingridge and Kelly, 2012) (Data S2). The alignment was manually trimmed using Mega7 (Kumar et al. 2016) to remove highly variable regions. Where genes were represented by multiple transcript variants, all but the longest variant was removed from the dataset. The zebrafish CR931806.1 
and msi homolog-like sequences were also removed because both were truncated. The trimmed alignment comprised 46 sequences (Data S3). The best-fitting model parameters $(L G+\mid+G 4)$ were estimated and consensus phylogenetic trees were run using Maximum Likelihood from 1000 bootstrap replicates, using IQTREE (Nguyen et al. 2015). The data were imported into ITOL (Letunic and Bork, 2016) to generate the pictorial representation. The tree was rooted on the branch between ophistokonts and archeoplastida, and all branches with less than $50 \%$ bootstrap support were collapsed.

\section{Plant strains and growth conditions}

Seeds were grown in Levington M3 compost in the greenhouse at $22^{\circ} \mathrm{C}$ with a $16 \mathrm{~h}$ light $\left(300 \mu \mathrm{mol}\right.$ photons $\left.\mathrm{m}^{-2} \mathrm{~s}^{-1}\right): 8 \mathrm{~h}$ dark cycle. The segregating, single-insert aog2-1 (SALK_007316) line was obtained from the Nottingham Arabidopsis Stock Centre. Segregating aog2-1 lines were genotyped using AOG2_LP and AOG2_RP primers to detect the WT allele), and LBa1 and AOG2_RP primers to detect the mutant allele. Primers were designed using the T-DNA Primer Design tool (SIGnAL). The primers AOG2_LP and AtMSI2_intron_2R were used to detect the presence of the WT allele in rescue lines.

\section{Reciprocal crosses}

To determine transmission of the mutation through the female, aog2-1/AOG2 mutant plants were cross-pollinated with WT pollen. To determine transmission of the mutation through the male, WT plants were cross-pollinated with aog2-1/AOG2 pollen. Progeny of crosses were genotyped by PCR to check for genetic segregation.

\section{RNA isolation and quantitative PCR}

Total RNA was prepared from pollen grains using the RNeasy plant kit (Qiagen). $1 \mu \mathrm{g}$ RNA was DNase treated (TURBO DNase, Ambion) and then cDNA was synthesised using Superscript III reverse transcriptase (Invitrogen). 
The expression of AOG2 was analysed by quantitative real-time Reverse Transcription PCR (qRT-PCR). Primers were designed to amplify a 100-150 bp fragment of each gene (Primer 3). Amplification was detected using the SYBR Green master mix (Life Technologies) according to the manufacturer's specifications on a StepOne ${ }^{\mathrm{TM}}$ Real-Time PCR System (Applied Biosystems). Cycling conditions were $95^{\circ} \mathrm{C}$ for $5 \mathrm{~min}$, and 40 cycles of $95^{\circ} \mathrm{C}$ for $15 \mathrm{~s}$ and $60^{\circ} \mathrm{C}$ for $1 \mathrm{~min}$. Three technical replicates were performed for each of three independent biological samples, alongside water controls. Ct values were calculated from raw amplification data using the Real-time PCR Miner software (http://www.ewindup.info/miner/). The mean Ct value between the three technical replicates was then calculated. Fold changes in gene expression were calculated relative to controls using the $2^{\wedge(-\Delta \Delta C t)}$ method. Two housekeeping genes were used as constitutive controls; EF1B (At5g19510) and UBP6 (At1g51710). To test for genomic DNA contamination, no RT controls were run to check that no amplification had occurred.

\section{Cloning and construct generation}

To generate the $A O G 2$ rescue construct, the AOG2 promoter sequence was amplified from WT Col-O genomic DNA using pAOG2FSall and pAOG2RBamHI and inserted into Sall/BamHI cut pBJ36 (Eshed et al., 2001) to create AOG2pro-ocs3'. The full-length AOG2 coding region was amplified from cDNA prepared from flower mRNA using AOG2StartBamHI and AOG2RinclStopXbal, and inserted into BamHI/Xbal cut AOG2pro-ocs3' to create AOG2pro:AOG2-ocs3'. The AOG2pro:AOG2-ocs3' cassette was transferred as a Notl fragment into the binary vector pMLBART (Eshed et al., 2001) and transformed into aog21/AOG2 plants by floral dipping (Clough and Bent, 1998). Transformed plants were selected on the basis of Basta resistance and presence of the T-DNA insertion. 
To generate the AOG2pro:AOG2-GFP reporter construct, the AOG2 promoter sequence was amplified from WT Col-O genomic DNA using pAOG2FSall and pAOG2RBamHI and inserted into Sall/BamHI cut pGreen (Hellens et al., 2000) to create AOG2pro-GFPter. The full-length AOG2 coding region (without the stop codon) was amplified from cDNA prepared from flower mRNA using AOG2StartBamHI and AOG2-StopNotl and inserted into BamHI/Notl cut AOG2pro-GFPter to create AOG2pro::AOG2-GFPter.

\section{Transient assays protoplasts}

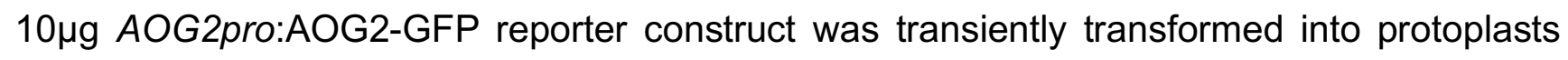
isolated from Physcomitrella patens as described in Moody et al. (2012).

\section{Silique measurements and seed counts}

Length measurements and seed counts were carried out for ten siliques derived from the primary inflorescence of each of three plants and repeated three times. Mature siliques were harvested and cleared in clearing solution (0.2 M NaOH, $1 \%$ SDS).

\section{Isolation of mature pollen grains}

Mature pollen grains were isolated from stage 13 flowers (Sanders et al., 1999). Flowers from approximately ten plants were collected and placed into $500 \mathrm{ml}$ flasks containing $100 \mathrm{ml}$ icecold $0.3 \mathrm{M}$ mannitol, and then vigorously shaken by hand for approximately 3 minutes. Pollen suspensions were then filtered through a $100 \mu \mathrm{m}$ nylon mesh into $50 \mathrm{ml}$ falcon tubes. Pollen grains were harvested by centrifugation at $5000 x g$ for 15 minutes. This step was repeated until all the pollen suspension had been used. After the final centrifugation, $2 \mathrm{ml}$ of $0.3 \mathrm{M}$ mannitol was left in the bottom of the tube and used to resuspend the pollen pellet and transfer it to a 2 $\mathrm{ml}$ eppendorf tube. The pollen grains were collected by centrifugation at maximum speed for 1 minute and then frozen in liquid nitrogen. 


\section{DAPI staining}

Pollen grains were harvested by centrifugation and resuspended in phosphate buffered saline (PBS) containing $2 \mu \mathrm{g} / \mathrm{ml}$ DAPI. Pollen grains were incubated overnight at room temperature in the dark. DAPI stained pollen grains were then imaged in a drop of water using a confocal microscope.

\section{Calcofluor staining}

Embryos and seed coats were separated using fine tweezers. Embryos were then submerged in a $10 \mu \mathrm{g} / \mathrm{ml}$ calcofluor solution for $5 \mathrm{~min}$, rinsed with water and then visualised using confocal microscopy.

\section{Alexander staining and determination of pollen viability}

Anthers were removed from mature flowers (stage 13, Sanders et al., 1999) and placed onto a microscope slide. A drop of Alexander staining solution was added using a Pasteur pipette. Alexander staining solution was prepared as previously described (Peterson et al., 2010). Stained pollen grains were observed using a Leica M165C microscope equipped with a QImaging Micropublishing 5.0 RTV camera. Two anthers were selected for each of three flowers per plant (three plants in total).

\section{Microscopy}

Fluorescence microscopy was carried out with a Zeiss LSM510 META confocal microscope. A 40x water immersive lens (C-Apochromat 40x/1.20 W) was used for all imaging. GFP was excited with the $458 \mathrm{~nm}$ laser line and detected with a $475-525 \mathrm{~nm}$ bandpass filter. Calcofluor was excited at $405 \mathrm{~nm}$ and detected with a LP420 nm filter. Other images were captured using either a Leica DMRB or a Leica M165C microscope, equipped with a QImaging Micropublishing 5.0 RTV camera. 


\section{Cryosectioning}

Detached inflorescences of WT Col-0 and heterozygous aog2-1/AOG2 lines were fixed at room temperature for $3 \mathrm{~h}$ in $4 \%$ paraformaldehyde in $0.05 \mathrm{M}$ PHEM buffer (Brown and Lemmon, 1995), pH 7.0, containing $5 \%$ DMSO and $0.01 \%$ TRITON-X100. Following fixation, the material was washed in buffer for $15 \mathrm{~min}$ and equilibrated for $2 \mathrm{~h}$ each in successive solutions of $7 \%$ and $12 \%$ sucrose in the same buffer/DMSO/TRITON combination. Inflorescences were then transferred to a drop of OCT Tissue Plus embedding medium (Scigen, CA, USA) on a slide, all bubbles removed using a dissecting needle, and then snapfrozen in fresh OCT Tissue Plus in a thin-walled plastic embedding mould floating in solid $\mathrm{CO}_{2}$ cooled pentane. The frozen blocks were sectioned at $10 \mu \mathrm{m}$ on a Reichert-Jung 2800 Frigocut cryostat and sections fixed onto Superfrost slides (Menzel, Saabruken, Germany) with a thin film of agar/gelatine (Brown and Lemmon, 1995). Sections were stained for $2 \mathrm{~h}$ in PBS containing $2 \mu \mathrm{g} / \mathrm{ml}$ DAPI and mounted in a $1: 1 \mathrm{mix}$ of glycerol and water containing $1 \%$ DABCO antifade (Sigma-Aldrich, USA) for confocal imaging using a Zeiss (Cambridge, UK) CSLM 410 (Brown and Lemmon, 1995).

\section{ACCESSION NUMBERS}

Accession numbers for genes described in this article are At3g07810 (AOG2) and At3g07800 (TK1). These can easily be found at either TAIR (https://www.arabidopsis.org) or Phytozome (https://phytozome.jgi.doe.gov/pz/portal.html).

\section{ACKNOWLEDGEMENTS}

We are grateful to Juliet C. Coates for providing the pGreen vector. The work was funded by a BBSRC (BB/M020517/1) grant to JAL.

\section{CONFLICT OF INTEREST}

We declare no conflict of interest. 


\section{SUPPORTING INFORMATION}

Figure S1. AOG2 expression in mature pollen grains.

Figure S2. Alignment of RRMs from AOG2 and human Msi2.

Data S1. Sequences comprising the orthogroup that includes Msi2

Data S2. Alignment of Msi2-related proteins (Mergalign)

Data S3. Trimmed alignment of Msi2-related proteins (46 sequences)

\section{AUTHOR CONTRIBUTIONS}

L.A.M. and J.A.L. conceived and designed the study; L.A.M. and J.A.L. wrote the manuscript with input from H.G.D.; E.R. performed reciprocal crosses; H.G.D. carried out the cryosectioning; J.A.L. performed phylogenetic analyses, assisted by D.M.E; L.A.M performed all other experimental work, with technical assistance (e.g. genotyping) from E.R. and R.C.

\section{REFERENCES}

1. Alonso JM, Stepanova AN, Leisse TJ, Kim CJ, Chen H, Shinn P, Stevenson DK, Zimmerman J, Barajas P, Cheuk R, et al.: Genome-Wide Insertional Mutagenesis of Arabidopsis thaliana. Science 2003, 301:653-657.

2. An D'ipp Olito † S, Agust In Arias L, Anah I Casalongu C, Pagnussat GC, Fiol DF: The DC1-domain protein VACUOLELESS GAMETOPHYTES is essential for development of female and male gametophytes in Arabidopsis. 2017, doi:10.1111/tpj.13486.

3. Brown RC, Lemmon BE: Methods in plant immunolight microscopy. Methods in cell biology 1995, 49:85-107.

4. Cao J: The Pectin Lyases in Arabidopsis thaliana: Evolution, Selection and Expression Profiles. PLoS ONE 2012, 7:e46944. 
5. Carvajal F, Garrido D, Jamilena M, Rosales R: Cloning and characterisation of a putative pollen-specific polygalacturonase gene ( CpPG1) differentially regulated during pollen development in zucchini ( Cucurbita pepo L.). Plant Biology 2014, 16:457-466.

6. Charlesworth A, Wilczynska A, Thampi P, Cox LL, MacNicol AM: Musashi regulates the temporal order of mRNA translation during Xenopus oocyte maturation. The EMBO Journal 2006, 25:2792-2801.

7. Clausen AR, Girandon L, Ali A, Knecht W, Rozpedowska E, Sandrini MPB, Andreasson E, Munch-Petersen B, Piškur J: Two thymidine kinases and one multisubstrate deoxyribonucleoside kinase salvage DNA precursors in Arabidopsis thaliana. FEBS Journal 2012, 279:3889-3897.

8. Clough SJ, Bent AF: Floral dip: a simplified method for Agrobacterium-mediated transformation of Arabidopsis thaliana. The Plant journal : for cell and molecular biology 1998, 16:735-43.

9. Collingridge PW, Kelly S: MergeAlign: improving multiple sequence alignment performance by dynamic reconstruction of consensus multiple sequence alignments. BMC Bioinformatics 2012, 13:117.

10. Cox JL, Wilder PJ, Gilmore JM, Wuebben EL, Washburn MP, Rizzino A: The SOX2Interactome in Brain Cancer Cells Identifies the Requirement of MSI2 and USP9X for the Growth of Brain Tumor Cells. PLOS ONE 2013, 8:e62857.

11. Cui H-H, Liao H-Z, Tang Y, Du X-Y, Chen L-Q, Ye D, Zhang X-Q: ABORTED GAMETOPHYTE 1 is required for gametogenesis in Arabidopsis. Journal of Integrative Plant Biology 2015, 57:1003-1016. 
12. Emms DM, Kelly S: OrthoFinder: solving fundamental biases in whole genome comparisons dramatically improves orthogroup inference accuracy. Genome Biology 2015, 16:157.

13. Eshed Y, Baum SF, Perea J V, Bowman JL: Establishment of polarity in lateral organs of plants. Current biology: CB 2001, 11:1251-60.

14. Forsthoefel NR, Klag KA, McNichol SR, Arnold CE, Vernon CR, Wood WW, Vernon DM: Arabidopsis PIRL6 Is Essential for Male and Female Gametogenesis and Is Regulated by Alternative Splicing. Plant physiology 2018, 178:1154-1169.

15. Griner LN, Reuther GW: Aggressive myeloid leukemia formation is directed by the Musashi 2/Numb pathway. Cancer biology \& therapy 2010, 10:979-82.

16. Gunter KM, McLaughlin EA: Translational control in germ cell development: A role for the RNA-binding proteins Musashi-1 and Musashi-2. IUBMB Life 2011, 63:n/an/a.

17. Guo K, Cui J, Quan M, Xie D, Jia Z, Wei D, Wang L, Gao Y, Ma Q, Xie K: The Novel KLF4/MSI2 Signaling Pathway Regulates Growth and Metastasis of Pancreatic Cancer. Clinical Cancer Research 2017, 23:687-696.

18. Guo M, Bier E, Jan LY, Jan YN: tramtrack acts downstream of numb to specify distinct daughter cell fates during asymmetric cell divisions in the Drosophila PNS. Neuron 1995, 14:913-25.

19. Guo M, Jan LY, Jan YN: Control of daughter cell fates during asymmetric division: interaction of Numb and Notch. Neuron 1996, 17:27-41. 
20. Hellens RP, Edwards EA, Leyland NR, Bean S, Mullineaux PM: pGreen: a versatile and flexible binary Ti vector for Agrobacterium-mediated plant transformation. Plant Molecular Biology 2000, 42:819-832.

21. Ito T, Kwon HY, Zimdahl B, Congdon KL, Blum J, Lento WE, Zhao C, Lagoo A, Gerrard G, Foroni L, et al.: Regulation of myeloid leukaemia by the cell-fate determinant Musashi. Nature 2010, 466:765-768.

22. Kaeda J, Ringel F, Oberender C, Mills K, Quintarelli C, Pane F, Koschmieder S, Slany $\mathrm{R}$, Schwarzer R, Saglio G, et al.: Up-regulated $M S I 2$ is associated with more aggressive chronic myeloid leukemia. Leukemia \& Lymphoma 2015, 56:21052113.

23. Kharas MG, Lengner CJ, Al-Shahrour F, Bullinger L, Ball B, Zaidi S, Morgan K, Tam W, Paktinat M, Okabe R, et al.: Musashi-2 regulates normal hematopoiesis and promotes aggressive myeloid leukemia. Nature Medicine 2010, 16:903-908.

24. Kudinov AE, Deneka A, Nikonova AS, Beck TN, Ahn Y-H, Liu X, Martinez CF, Schultz FA, Reynolds S, Yang D-H, et al.: Musashi-2 (MSI2) supports TGF- $\beta$ signaling and inhibits claudins to promote non-small cell lung cancer (NSCLC) metastasis. Proceedings of the National Academy of Sciences 2016, 113:6955-6960.

25. Kumar S, Stecher G, Tamura K: MEGA7: Molecular Evolutionary Genetics Analysis Version 7.0 for Bigger Datasets. Molecular Biology and Evolution 2016, 33:1870-1874.

26. Lan L, Xing M, Douglas JT, Gao P, Hanzlik RP, Xu L: Human oncoprotein Musashi$2 \mathrm{~N}$-terminal RNA recognition motif backbone assignment and identification of RNA-binding pocket. Oncotarget 2017, 8:106587-106597. 
27. Letunic I, Bork P: Interactive tree of life (iTOL) v3: an online tool for the display and annotation of phylogenetic and other trees. Nucleic Acids Research 2016, 44:W242-W245.

28. Li N, Yousefi M, Nakauka-Ddamba A, Li F, Vandivier L, Parada K, Woo D-H, Wang S, Naqvi AS, Rao S, et al.: The Msi Family of RNA-Binding Proteins Function Redundantly as Intestinal Oncoproteins. Cell reports 2015, 13:2440-2455.

29. Li S, Liu L, Zhuang X, Yu Y, Liu X, Cui X, Ji L, Pan Z, Cao X, Mo B, et al.: MicroRnAs Inhibit the Translation of Target mRNAs on the Endoplasmic Reticulum in Arabidopsis. Cell 2013, 153:562-574.

30. Li W, Flores DC, Füßel J, Euteneuer J, Dathe H, Zou Y, Weisheit W, Wagner V, Petersen J, Mittag M: A Musashi Splice Variant and Its Interaction Partners Influence Temperature Acclimation in Chlamydomonas. Plant physiology 2018, 178:1489-1506.

31. McLaughlin E, Hime G, Sutherland J, Siddall N: RNA binding proteins in spermatogenesis: an in depth focus on the Musashi family. Asian Journal of Andrology 2015, 17:529.

32. Moody LA, Saidi Y, Smiles EJ, Bradshaw SJ, Meddings M, Winn PJ, Coates JC: ARABIDILLO gene homologues in basal land plants: species-specific gene duplication and likely functional redundancy. Planta 2012, 236:1927-1941.

33. Nakamura M, Okano H, Blendy JA, Montell C: Musashi, a neural RNA-binding protein required for Drosophila adult external sensory organ development. Neuron 1994, 13:67-81. 
34. Negi S, Pandey S, Srinivasan SM, Mohammed A, Guda C: LocSigDB: a database of protein localization signals. Database : the journal of biological databases and curation 2015, 2015.

35. Nguyen L-T, Schmidt HA, von Haeseler A, Minh BQ: IQ-TREE: A Fast and Effective Stochastic Algorithm for Estimating Maximum-Likelihood Phylogenies. Molecular Biology and Evolution 2015, 32:268-274.

36. Oh S-A, Jeon J, Park H-J, Grini PE, Twell D, Park SK: Analysis of gemini pollen 3 mutant suggests a broad function of AUGMIN in microtubule organization during sexual reproduction in Arabidopsis. The Plant Journal 2016, 87:188-201.

37. Park SK, Howden R, Twell D: The Arabidopsis thaliana gametophytic mutation gemini pollen1 disrupts microspore polarity, division asymmetry and pollen cell fate. Development (Cambridge, England) 1998, 125:3789-99.

38. Park SK, Twell D: Novel patterns of ectopic cell plate growth and lipid body distribution in the Arabidopsis gemini pollen1 mutant. Plant physiology 2001, 126:899-909.

39. Park S, Rahman D, Oh S, Twell D: Gemini pollen 2, a male and female gametophytic cytokinesis defective mutation. Sexual Plant Reproduction 2004, $17: 63-70$.

40. Peterson R, Slovin JP, Chen C: A simplified method for differential staining of aborted and non-aborted pollen grains. International Journal of Plant Biology 2010, $1: 13$. 
41. Sanders PM, Bui AQ, Weterings K, Mclntire KN, Hsu Y-C, Lee PY, Truong MT, Beals TP, Goldberg RB: Anther developmental defects in Arabidopsis thaliana malesterile mutants. Sexual Plant Reproduction 1999, 11:297-322.

42. Siddall NA, McLaughlin EA, Marriner NL, Hime GR: The RNA-binding protein Musashi is required intrinsically to maintain stem cell identity. Proceedings of the National Academy of Sciences 2006, 103:8402-8407.

43. Sutherland JM, McLaughlin EA, Hime GR, Siddall NA: The Musashi family of RNA binding proteins: master regulators of multiple stem cell populations. Advances in experimental medicine and biology 2013, 786:233-45.

44. Sutherland JM, Fraser BA, Sobinoff AP, Pye VJ, Davidson T-L, Siddall NA, Koopman P, Hime GR, McLaughlin EA: Developmental Expression of Musashi-1 and Musashi-2 RNA-Binding Proteins During Spermatogenesis: Analysis of the Deleterious Effects of Dysregulated Expression1. Biology of Reproduction 2014, 90:92.

45. Sutherland JM, Sobinoff AP, Fraser BA, Redgrove KA, Siddall NA, Koopman P, Hime GR, McLaughlin EA: RNA binding protein Musashi-2 regulates PIWIL1 and TBX1 in mouse spermatogenesis. Journal of Cellular Physiology 2018, 233:3262-3273.

46. Twell D, Park SK, Hawkins TJ, Schubert D, Schmidt R, Smertenko A, Hussey PJ: No Title. 2002, 4.

47. Whittington AT, Vugrek O, Wei KJ, Hasenbein NG, Sugimoto K, Rashbrooke MC, Wasteneys GO: MOR1 is essential for organizing cortical microtubules in plants. Nature 2001, 411:610-613. 
48. Xu J, Zhang L, Yang D-L, Li Q, He Z: Thymidine kinases share a conserved function for nucleotide salvage and play an essential role in Arabidopsis thaliana growth and development. New Phytologist 2015, 208:1089-1103.

49. Zhang H, Tan S, Wang J, Chen S, Quan J, Xian J, Zhang S shuai, He J, Zhang L: Musashi2 modulates K562 leukemic cell proliferation and apoptosis involving the MAPK pathway. Experimental Cell Research 2014, 320:119-127.

50. Zhong W, Feder JN, Jiang MM, Jan LY, Jan YN: Asymmetric localization of a mammalian numb homolog during mouse cortical neurogenesis. Neuron 1996, $17: 43-53$.

51. Zimmermann P, Hirsch-Hoffmann M, Hennig L, Gruissem W: GENEVESTIGATOR. Arabidopsis Microarray Database and Analysis Toolbox. PLANT PHYSIOLOGY 2004, 136:2621-2632.

52. Zong Z, Zhou T, Rao L, Jiang Z, Li Y, Hou Z, Yang B, Han F, Chen S: Musashi2 as a novel predictive biomarker for liver metastasis and poor prognosis in colorectal cancer. Cancer medicine 2016, 5:623-30. 


\section{FIGURE LEGENDS}

\section{Figure 1. Phylogenetic analysis of Musashi homologs}

Inferred phylogenetic tree from maximum likelihood analysis of 46 amino acid sequences retrieved from 11 genomes (see Data S1-S3 for accession numbers and alignment). Bootstrap values are given for each node. The tree was rooted on the branch between archeoplastida and ophistokonts and all branches with less than $50 \%$ bootstrap support were collapsed. Independent duplications in both groups resolved two clades in each ('plants l' - dark green; 'plants II' - light green; Dazap - light purple; Msi - dark purple).

\section{Figure 2. Expression of Arabidopsis Musashi-related genes}

Summary of GENEVESTIGATOR ATH1 array data for the seven Msi orthologs in the 'plants II' clade. Dark blue boxes represent the highest signal intensity (100 \%) whereas white boxes denote the absence of a signal.

\section{Figure 3. AOG2 localises to the endoplasmic reticulum}

(a) The AOG2 protein (495 residues) contains two RNA recognition motifs (RRM1, 6-82; RRM2, 108-185) and an ER targeting signal (157-159). (b) AOG2-GFP localisation in protoplasts. Magenta represents autofluorescence, blue represents GFP and overlay represents merged autofluorescence and GFP images. Scale bar, $10 \mu \mathrm{m}$.

\section{Figure 4. $\operatorname{aog} 2$ mutants exhibit fertility defects}

(a) T-DNA insertion (SALK_007316) positioned between the open reading frames of AOG2 and TK1 genes. (b) Quantitative RT-PCR data showing the relative expression of AOG2 in pollen isolated from WT (Col-0) and aog2-1/AOG2 plants. $t$-test, *, $\mathrm{P}<0.005$. (c) Mean silique length in mature WT and aog2-1/AOG2 plants. $t$-test, ${ }^{* * *}, P<0.001$. (d) Mean number of seeds in WT and aog2-1/AOG2 plants. $t$-test, ${ }^{* * *}, \mathrm{P}<0.001$. 


\section{Figure 5. Genetic transmission of aog2}

(a) The number of WT (+/+) and aog2-1/AOG2 (aog2-1/+) individuals resulting from reciprocal test crosses between aog2-1/AOG2 and WT (Col-0) plants. The transmission efficiency (TE) was calculated in each case. (b) Predicted frequencies of WT, aog2-1/+ and aog2-1/aog2-1 progeny derived from self-progeny of aog2-1/+ plants. (c) Observed and expected numbers of WT, aog2-1/+ and aog2-1/aog2-1 progeny derived from self-progeny of aog2-1/+ plants.

Figure 6. Complementation with full-length AOG2 cDNA restores viability to aog21/aog2-1 mutants

Representative images of (a) mature WT, (b) aog2-1/+, (c) aog2-1/aog2-1 complementation line 5, (d) aog2-1/aog2-1 complementation line 6. Scale bar, $10 \mathrm{~mm}$. (e) Mean silique length in (from left to right) WT, aog2-1/AOG2, aog2-1/aog2-1, aog2-1/aog2-1 complementation line 5 and aog2-1/aog2-1 complementation line 6. $t$-test, ${ }^{* * *}, \mathrm{P}<0.001$.

Figure 7. AOG2 is essential for female gametophyte development.

(a, c) Cleared siliques from WT and aog2-1/+ respectively. Scale bar, $5 \mathrm{~mm}$. Aborted seeds denoted by an arrow in (c). (b, d) Dissected siliques from WT and aog2-1/+ respectively. Scale bar, $1 \mathrm{~mm}$. Aborted ovules denoted by red arrows in (d). (e) Percentage of aborted seeds per silique in WT and aog2-1/+. t-test, ${ }^{* *}, \mathrm{P}<0.001$. (f-i) Developmental arrest observed at the two-cell stage (f), globular stage (g) and late heart (h) of embryos in aog2-1/+. Normal embryo development was otherwise observed (i).

\section{Figure 8. AOG2 is essential for male gametophyte development.}

(a) Diagram depicting the stages of pollen development. PMI and PMII denote Pollen Mitosis I and Pollen Mitosis II respectively. (b, c) Alexander-stained anthers from WT (b) and aog2$1 /+(c)$ containing viable (red) and non-viable or aborted pollen grains (green). Scale bar, 100 $\mu \mathrm{m}$. (d) The mean number of pollen grains per anther in WT and aog2-1/+. $t$-test, ${ }^{* * *}, \mathrm{P}<0.001$. 
(e-g) Normal tricellular pollen in WT (e) and an equal mixture of tricellular pollen (f) and aborted unicellular microspores (g) in aog2-1/+. (h-k) DAPI-stained cryostat-sectioned anthers from WT (h) and aog2-1/+ (i-k). Abnormal asymmetric cell division shown in (k). Scale bar, $5 \mu \mathrm{m}$.

Figure S1. AOG2 is expressed in mature pollen grains.

(a) Autofluorescence in WT pollen grains. (b-d) pAOG2:AOG2-GFP expression in pollen grains (b), in pollen grains within the anther (c) and in pollen grains on stigma (d). Red represents autofluorescence, green represents GFP and overlay represents merged autofluorescence and GFP images. Scale bar, $50 \mu \mathrm{m}$.

\section{Figure S2. The AOG2 RRMs are similar to those from human Msi2.}

An alignment of both RRM1 and RRM2 from AOG2 and human Msi2. Identical amino acids are denoted by an asterisk $\left(^{*}\right)$, conserved amino acids denoted by a colon (:) and semiconserved amino acids by a period (.). Numbers to the left and right of the alignment correspond to the relative position of amino acids from the start residue, methionine. 


\section{Figure 1}

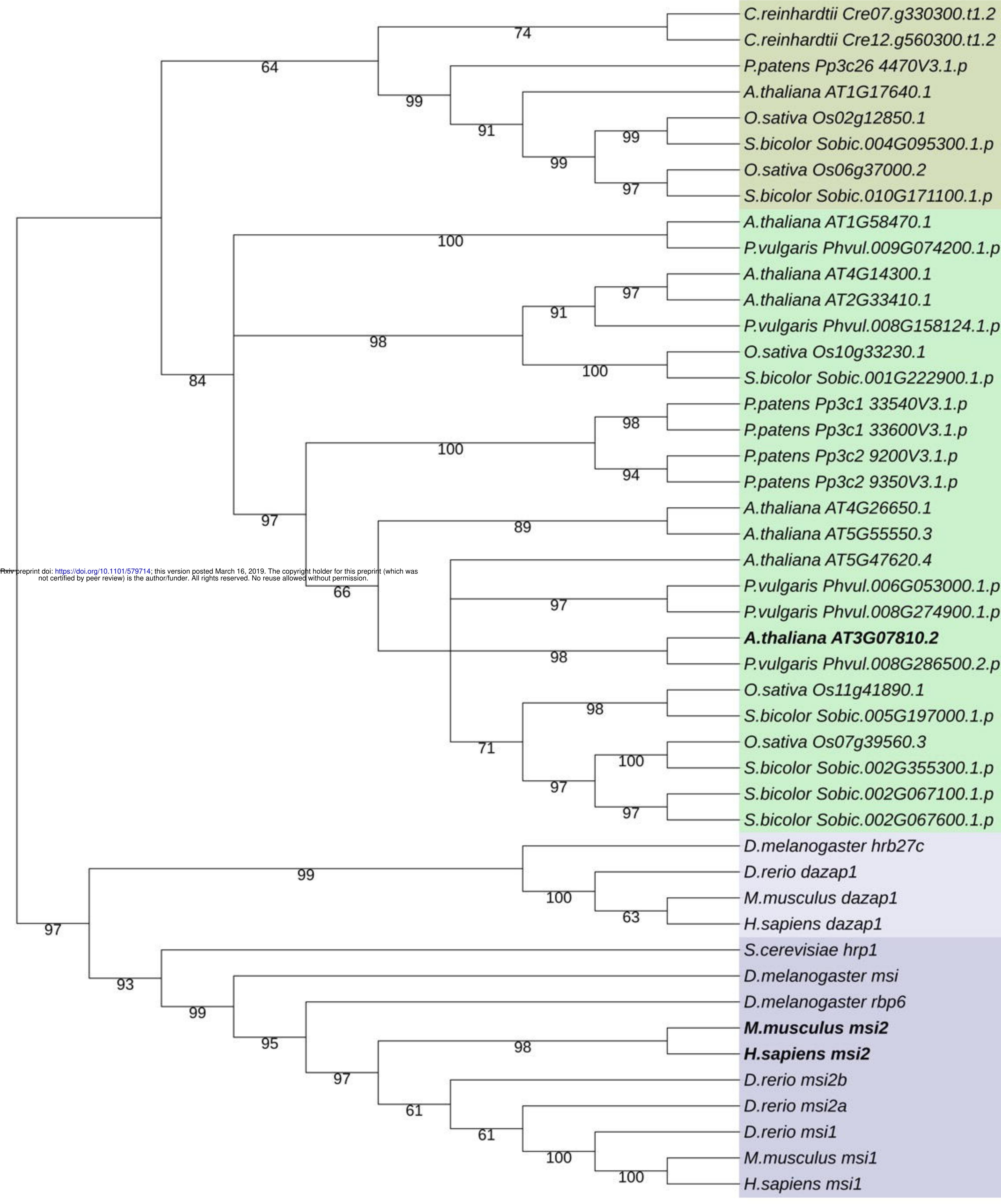


$0 \%$

Percent of Expression Potential

$\nabla$ inflorescence

$\mathbf{v}$ raceme

$\checkmark$ flower

$\nabla$ stamen

$\nabla$ anther

pollen

abscission zone

$\nabla$ pistil

$\checkmark$ carpel

stigma

$\checkmark$ ovary ovule

petal

sepal

pedicel

v silique

$\nabla$ seed

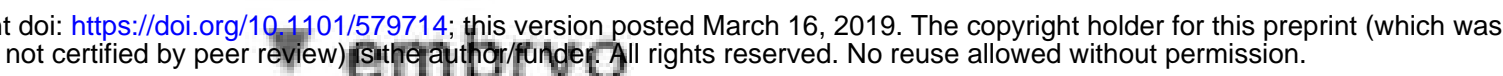

suspensor

$\nabla$ endosperm

micropylar endosperm

$\nabla$ nonmicropylar endosperm

peripheral endosperm

chalazal endosperm

$\nabla$ testa

general seed coat

chalazal seed coat

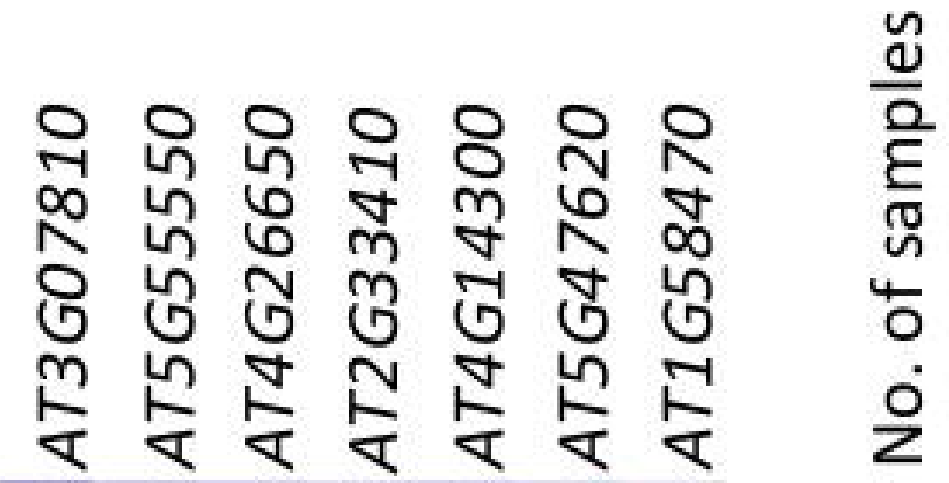

801

327

324

118

52

52

15

40

11

3

6

2

6

6

3

372

323

40

2

41

8

22

10

12

25

8

13

7

7

replum 


\section{Figure 3}

(a)

157-159 ER targeting signal (DSE)

\begin{tabular}{|l|l|l|l|l|}
\hline 1 & AOG2 & AOG \\
\hline & RRM1 (6-82) & RRM2 (108-185) & \\
\hline
\end{tabular}
495

(b)

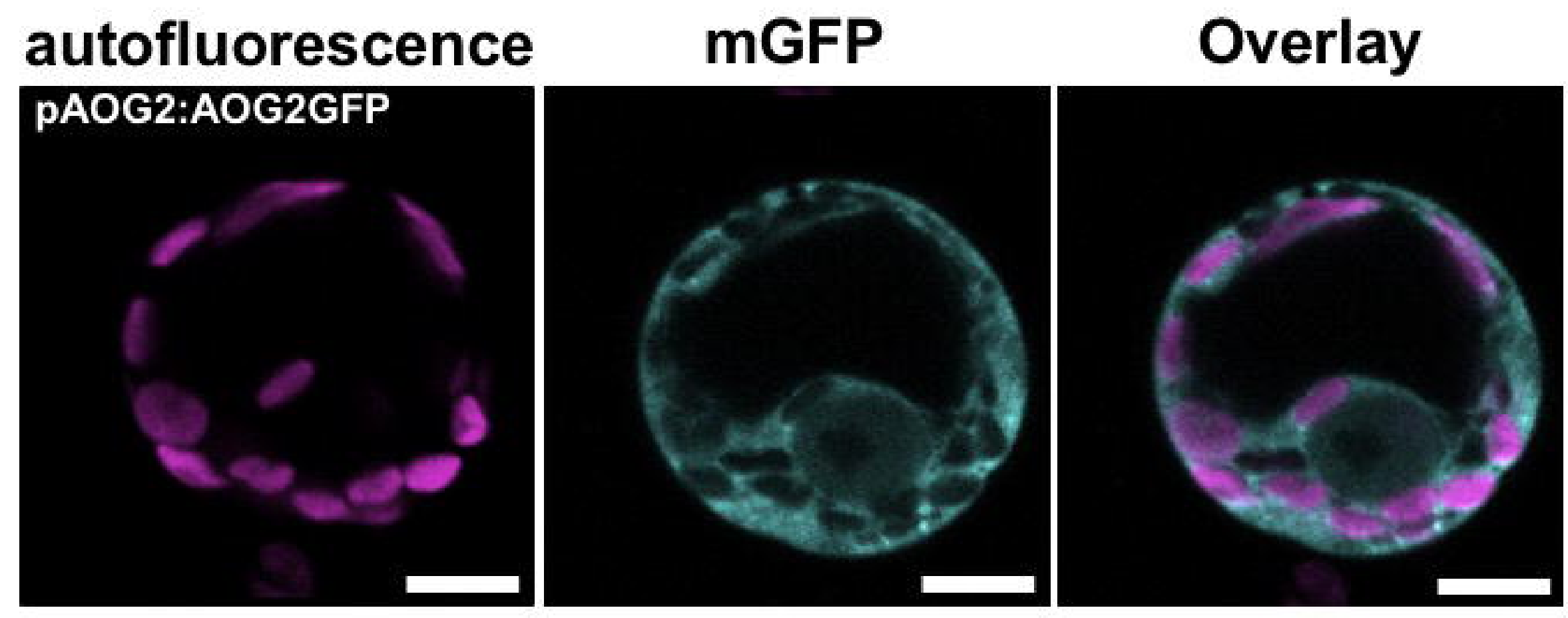


Figure 4

(a)
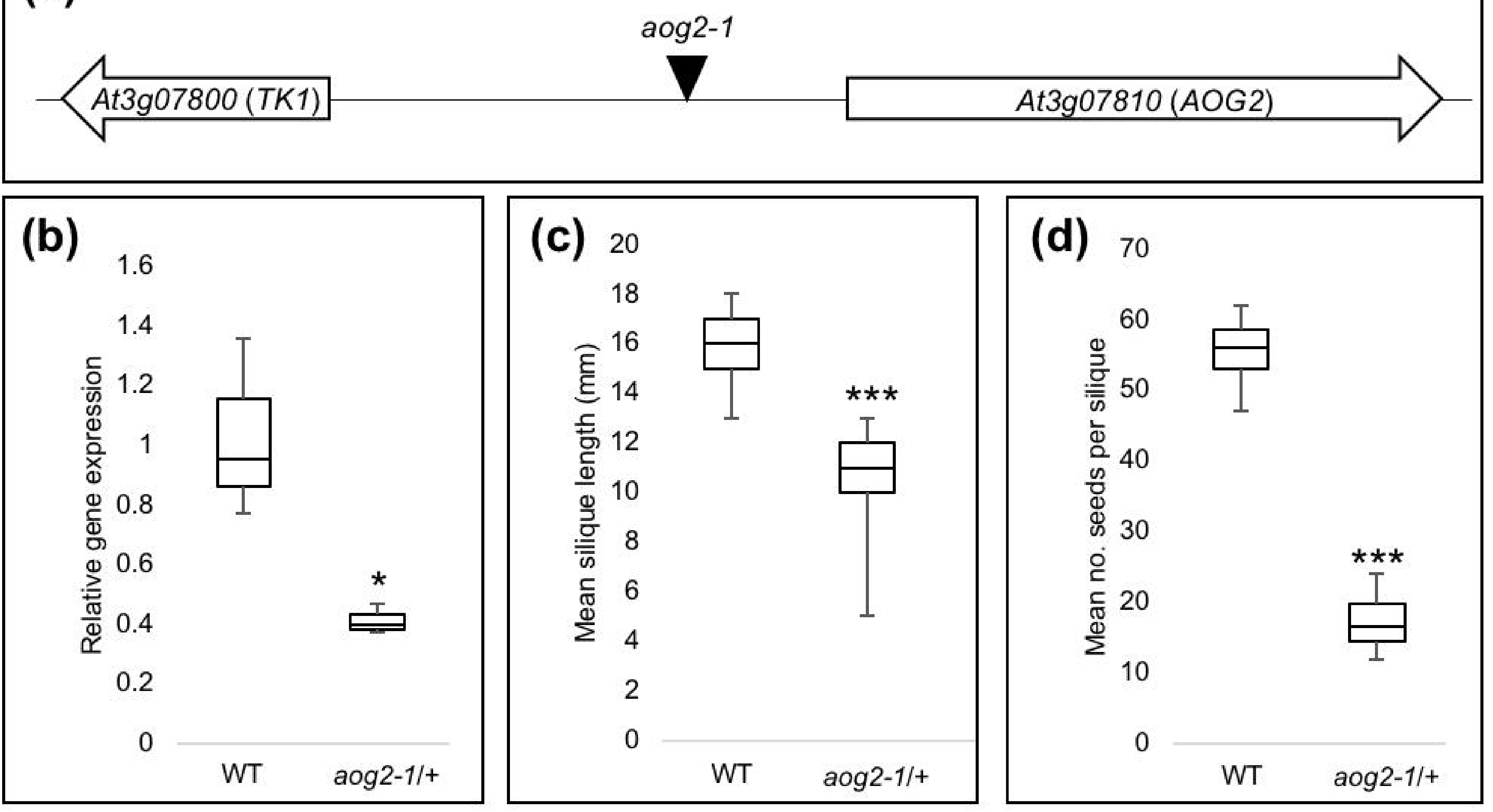
(a)

\begin{tabular}{cccccccc}
\hline Transmission & Cross & aog2-1/+ & $+/+$ & $\%$ & aog2-1/+ $\%+/+$ & TE (\%) \\
\hline Male & $+/+\mathrm{X}$ aog2-1/+ & 42 & 87 & 32.6 & 67.4 & 48.3 \\
Female & aog2-1/+ X $+/+$ & 50 & 140 & 26.3 & 73.7 & 35.7 \\
\hline & & & \multicolumn{4}{c}{ TE $=(\text { mutant } / W T)^{\star} 100$}
\end{tabular}

(b)

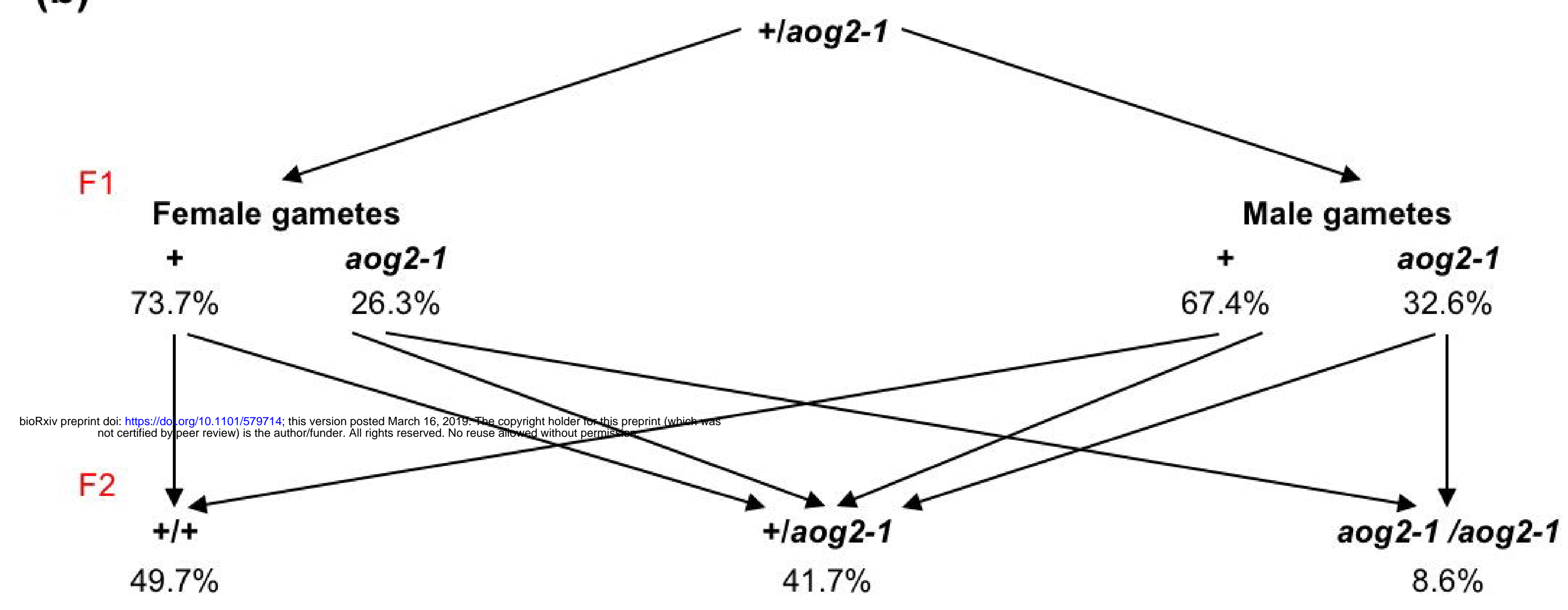

(c)

\begin{tabular}{ccccc}
\hline Self progeny of atmsi2-1/+ & $+\mathbf{+}$ & aog2-1/+ & aog2-1/aog2-1 & TOTAL \\
\hline Expected & $264.90(49.7 \%)$ & $222.23(41.7 \%)$ & $45.84(8.6 \%)$ & $533(100 \%)$ \\
Observed & $319(59.8 \%)$ & $214(40.2 \%)$ & $0(0 \%)$ & $533(100 \%)$ \\
\hline
\end{tabular}


Figure 6

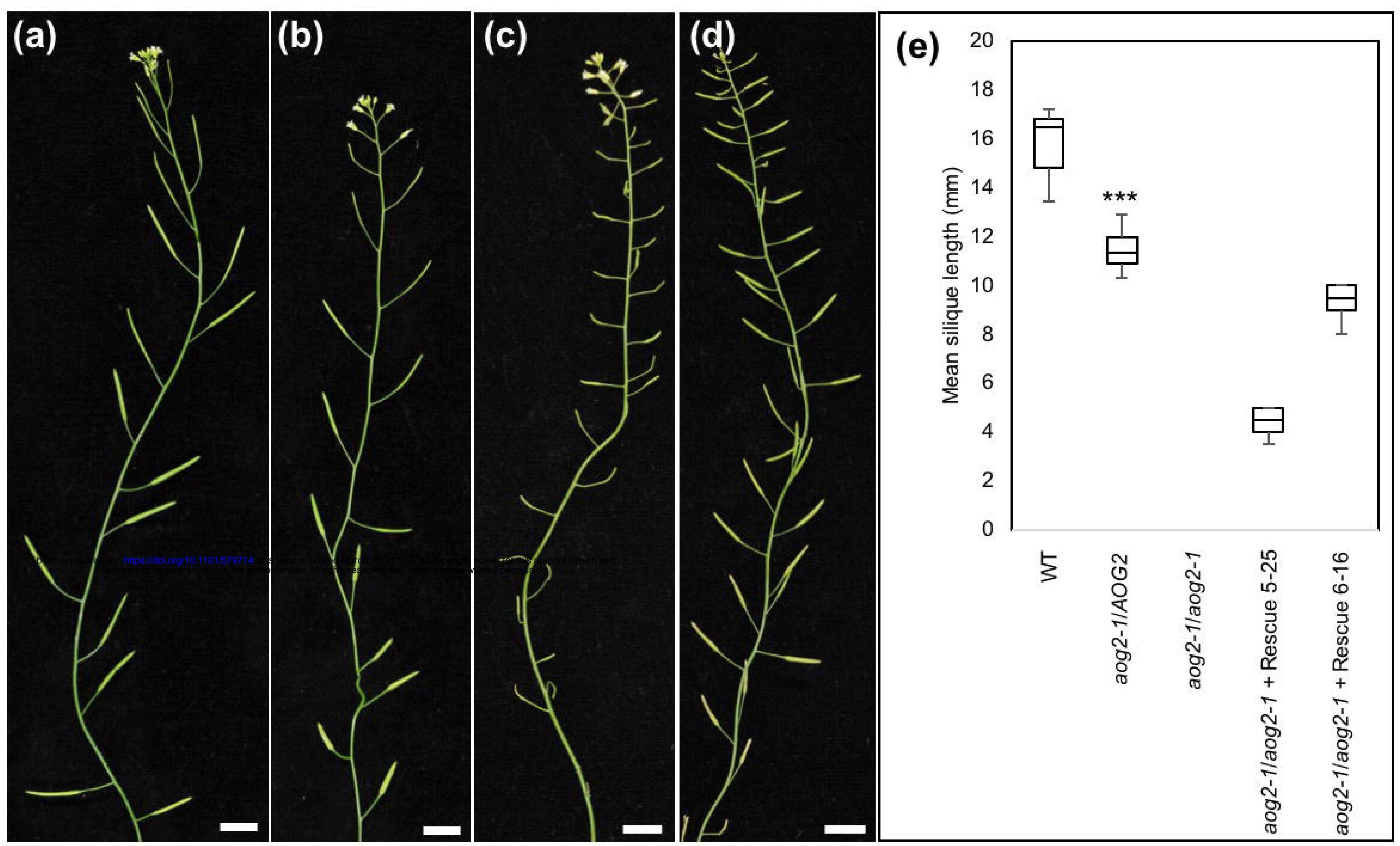


Figure 7

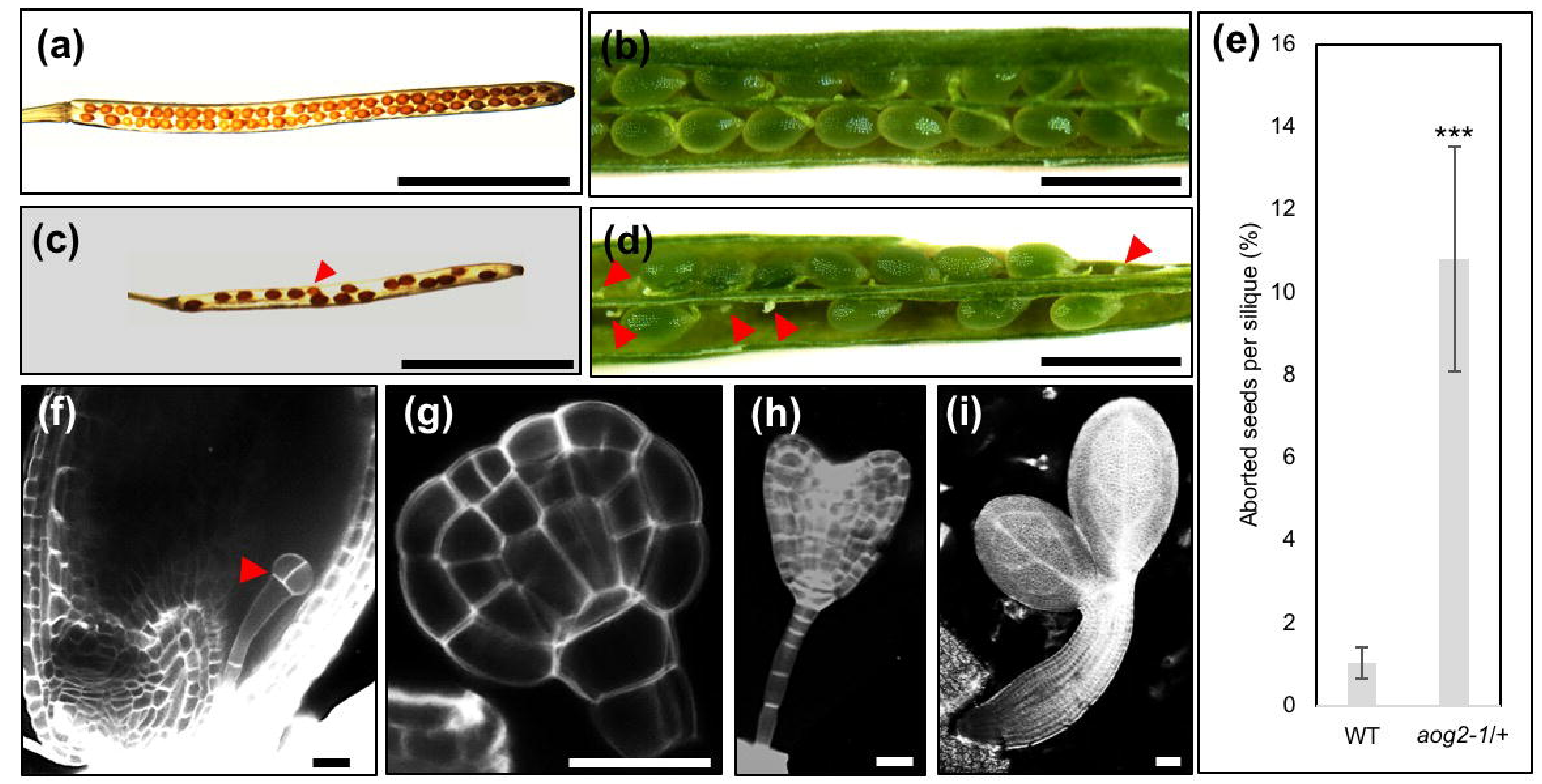




\section{Figure 8}
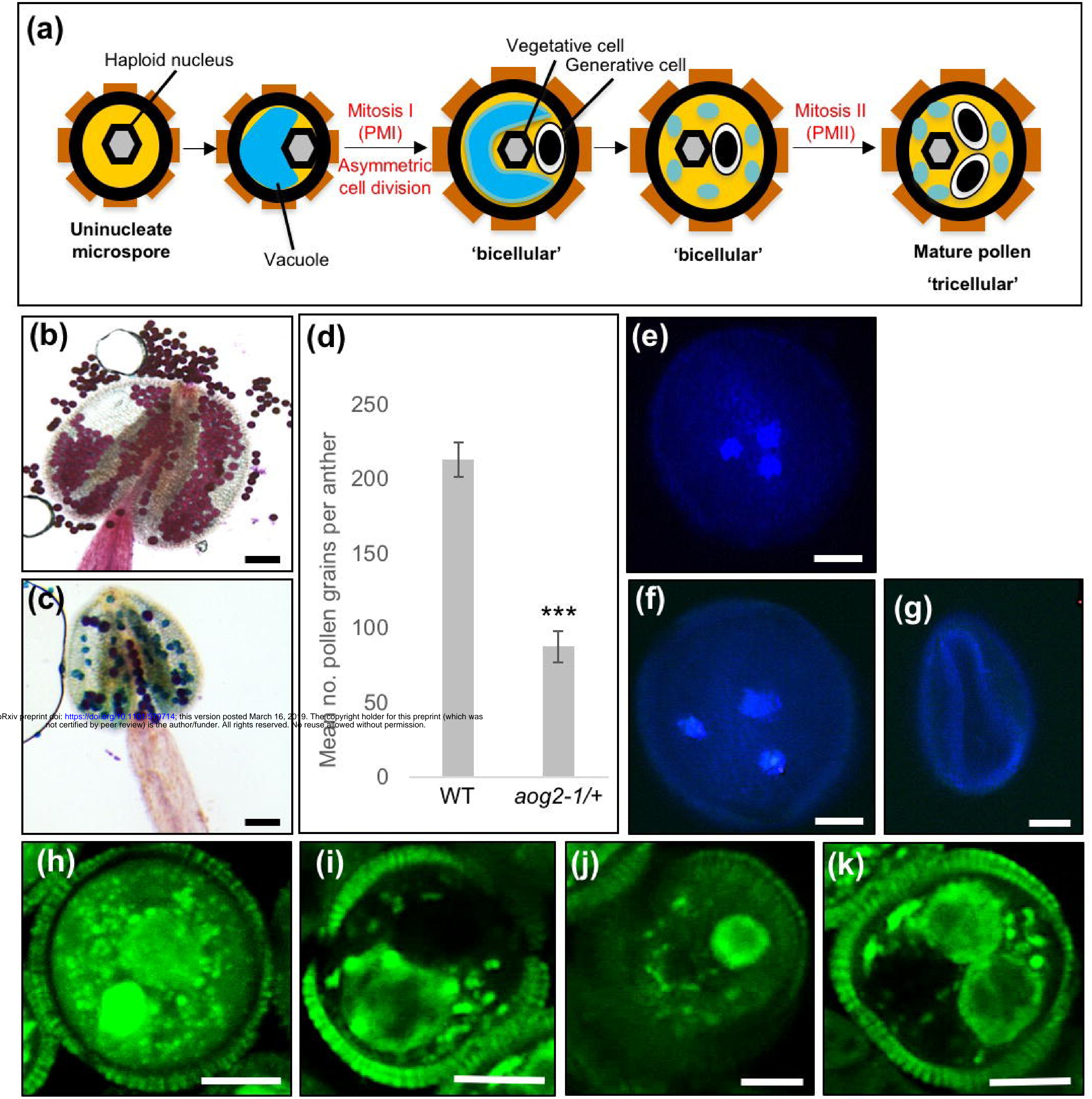
Figure S1

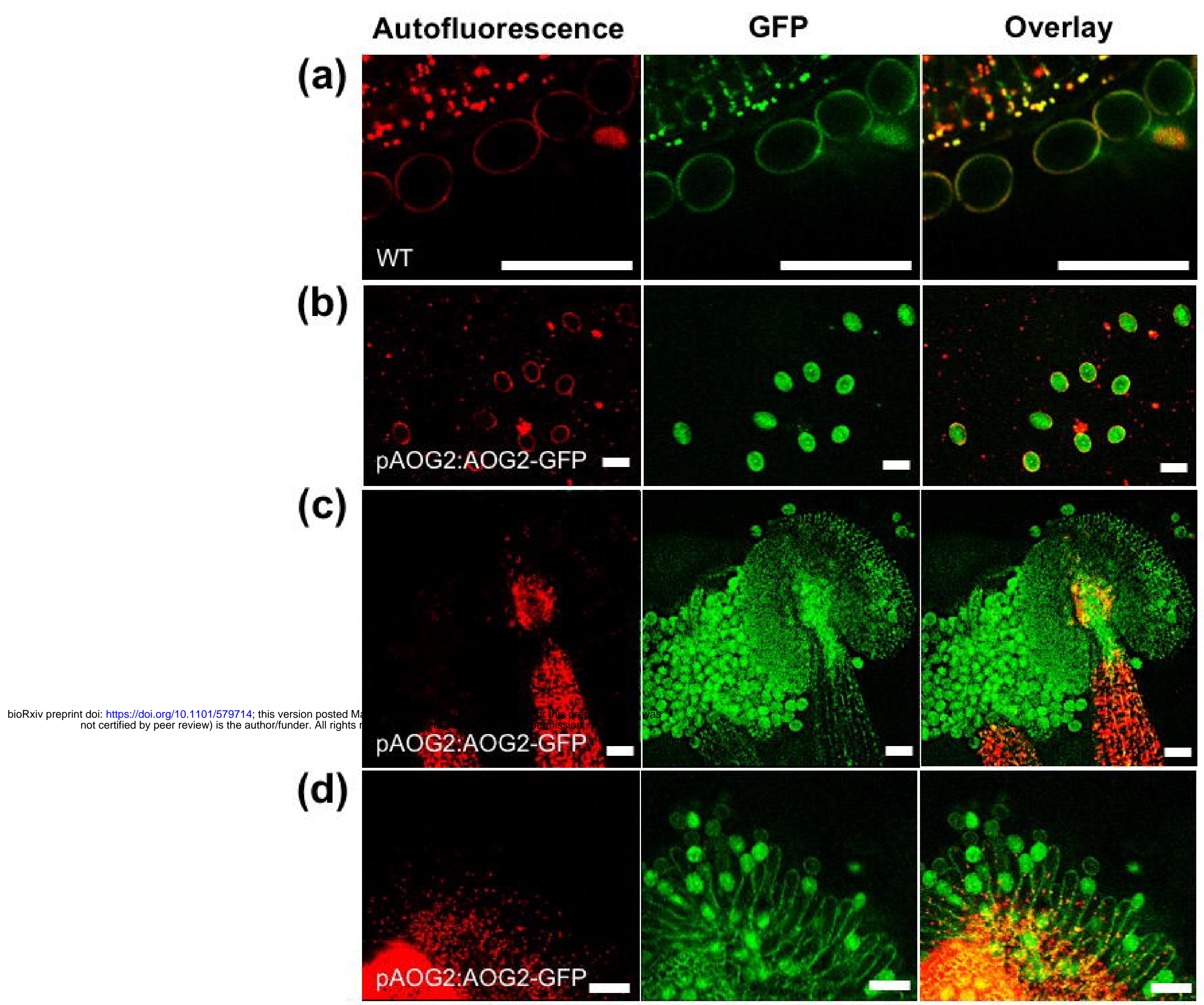


Figure S2

AOG1_RRM1 Msi2_RRM1

AOG2 RRM2 Msi2_RRM2
7

KIFIGGISW

KMFIGGISWOTSPDSLRDYFSKFGEIRECMVMRDPTTKR

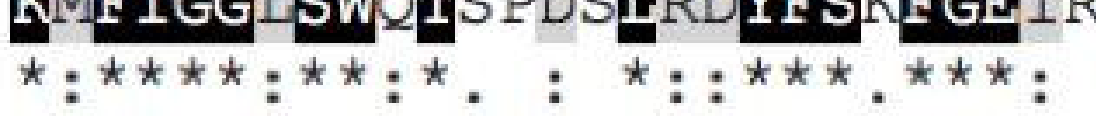

109

111
KIFVGGLPSSVTESD
KIFVGGLSANTVVED

\section{TFEQFGTTTD}

YFEQFGKVE
RGFGFV

FADPAVA

FADPA

AEIVITE-KHNIDGRLVEAK

DKVLGQPHHELDSKTIDPK
$: *::: *: * *::: *$

78

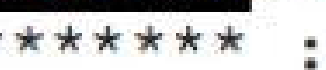

PRGFGE ITYDSEEAVEKVLLKTFHELNGKMVEVK RGFGEVTFENEDVVEKV CEI HFHEINNKMVECK
181 